\title{
Agricultural Origins and Frontiers in South Asia: A Working Synthesis
}

\author{
Dorian Q. Fuller
}

Published online: 17 February 2007

(C) Springer Science+Business Media, LLC 2007

Due to a technical problem a number of typographical errors made it into the published version of this paper. A selection of those which may cause confusion are indicated here.

p. 2, line 30, should read: ". . as research in the eastern Mediterranean indicates ..."

p. 3, Fig. 1 caption, third line, should include: "These rapidly expanding settlements may include recruitment from..."

p. 8, Fig. 5 caption, should read "... herbarium collections in Calcutta and Pune."

p. 10 , line 25 , should read: "but the sequence needs to be re-dated along the lines indicated in Fig. 6" [not Fig. 5]

p. 11, Fig. 7 caption, no (4) should read "Lal Qila" [not Quila].

p. 12, last cited reference should be: Zohary, Tchernov and Horwitz, 1998.

p. 20 , line 21 , should read "... although their domestication status or dating remains"

p. 20, last two lines, should read: "...the clear antiquity of agriculture based on these crops"

p. 22, line 29, should read: “. . . as indicated in Fig. 8” [not Fig. 7].

p. 23, line 17, should read: “...T. durum/T. turgidum, which can also be"

P. 26, citation "Legge \& Harris, 1996" should be Legge, 1996.

p. 30, line 20, the phrase "from collagen dates" should be omitted.

The online version of the original article can be found at http://dx.doi.org/10.1007/s10963-006-9006-8

D. Q. Fuller $(\bowtie)$

Institute of Archaeology, University College London, 31-34 Gordon Square, London WC1H OPY, UK e-mail: d.fuller@ucl.ac.uk 